\title{
Biorational method for controlling the abundance of Cydia pomonella $L$. in apple agrocenoses of the Krasnodar region
}

\author{
Marina Podgornaya*1, Svetlana Prakh $^{1}$, Anfisa Vasilchenko $^{1}$, and Nadezhda Didenko ${ }^{1}$ \\ ${ }^{1}$ Federal State Budget Scientific Institution «North Caucasian Federal Scientific Center of Horticulture, \\ Viticulture, Wine-making», 39 str. 40 Let Pobedy, Krasnodar, 350901, Russia
}

\begin{abstract}
In the region of Krasnodar Territory, Cydia pomonella L. belongs to the dominant pests of the apple tree, against which 8-10 treatments with insecticides are carried out during the growing season. In world practice, pheromones Shin-Etsu ${ }^{\circledR}$ MD CTT, D and BRIZ ${ }^{\circledR}$ are used in apple agrocenoses for the control of $C$. pomonella. abstention or reduction of insecticidal treatments leads to a decrease in the pesticide load on the agrocenosis of the garden by a factor of two or more. The objective of our research was to determine the biological pheromones effectiveness in controlling $C$. pomonella quantity. The test was carried out in two horticultural zones of the Krasnodar Territory, in areas with different numbers of phytophage. The experiment as a result, it was found that in the experimental plots the percentage of damaged fruits in the drop was 1.3$1.5 \%$. Fruit damage wasn't observed in a removable crop, which corresponds to the results of the standard version, with the use of insecticidal treatments. It was found that the pheromones usage in the Black Sea horticultural zone of the Krasnodar Territory is economically feasible. Cost reduction for the purchase of insecticides amounted to $9089.2 \mathrm{rub} / \mathrm{ha}$, a decrease in pesticide load by $70 \%$.
\end{abstract}

\section{Introduction}

Need arises to switch to new strategies for protection against lepidoptera pests, in particular, against Cydia pomonella, in fruit plantations, in recent years. This concept should primarily be based on phytosanitary optimization of agroecosystems, expanding the list of plant protection products. The main condition for the applied pesticides is the selective ability and the preparations ecological safety. Currently, insecticides are used from the organophosphorus compounds group, carbamates and pyrethroids, which are highly toxic drugs for pests and garden agrocenosis. The contemporary substances of a different type include bioregulators that don't directly affect the insect's body, but are involved in the transmission of chemical signals that control life processes at the physiological level.

\footnotetext{
* Corresponding author: podgornayame@mail.ru
} 
Cydia pomonella is one of the main destructive species in apple plantations of the Krasnodar Territory. The phytophage develops in three full generations, therefore 8-10 insecticidal treatments must be carried to protect the crop in the region [1]. Frequent use of pesticides for a series of years leads to significant changes in agrobiocenosis, as a result - the formation of resistance, the disappearance of entomophages, and rotation of the prevailing species. With the advent of pheromones and modern technologies, which over a long period are dosed and regularly release volatile substances from dispensers, it has become possible to reduce the quantity of chemical treatments. Specifics of pheromones are - effective control of the phytophage population at an economically imperceptible level, selectivity of action, absence of toxicity for mammals and entomophages, as well as high efficiency with minimal amounts and rapid degradation in the environment [2-5].

In 2015, twin-tubes (plastic dispensers) Shin-Etsu ${ }^{\circledR}$ MD CTT, D were created in Japan, they were produced by Summit Agro and German scientists from BASF synthesized pheromones with the trade name BRIZ® (RAK in Europe) [6-7].

Analysis of the global pheromone market revealed that Lymantria dispar and C. pomonella account for about $68 \%$ of the total world pheromone consumption [8].

The purpose of our research was to determine the biological effectiveness of pheromones Shin-Etsu® MD CTT, D and BRIZ® in controlling the number of $C$. pomonella.

The research tasks included: to evaluate the biological effectiveness of pheromones ShinEtsu ${ }^{\circledR}$ MD CTT, D and BRIZ® in the control of $C$. pomonella in areas with different initial numbers of phytophage; determine if there is a side effect of pheromones on other types of pests in apple plantations; to develop a technology for regulating the number of $C$. pomonella based on a complex of communication methods and pest activity.

\section{Materials and methods}

Evaluation of the effectiveness of pheromones BRIZ ${ }^{\circledR}$ and Shin-Etsu ${ }^{\circledR}$ MD CTT, D in controlling the number of $C$. pomonella was carried out by specialists of the Scientific Center for Plant Protection and Biotechnology «North Caucasian Federal Scientific Center of Horticulture, Viticulture, Wine-making» in specialized fruit growing farms of the Krasnodar Territory: Loris ZAO (central zone) and Novomikhaylovskoe agricultural enterprise (Black Sea zone) in 2017 - 2019.

In production field experiments ( 3 ha), two types of pheromones were used: Shin-Etsu ${ }^{\circledR}$ MD CTT, D - dispenser E, E-8,10-Dodecadien-1-ol 2.2x10-4 + dispenser 1- Dodecanol 1.2x10- $4+1$-Tetradecanol dispenser $2.76 \times 10-5 \mathrm{~kg} /$ dispenser) and BRIZ® complex threecomponent pheromone - a vapor-generating product in a dispenser $(178 \mathrm{mg} /$ codlemon +42 $\mathrm{mg} /$ ntetradecyl acetate).

The tests were carried out according to the male disorientation method, the placement scheme recommended by the manufacturers.

The dispensers were hung in the garden during the "beginning of flowering" phenophase, i.e. before the overwintered generation of $C$. pomonella began to fly. The dynamics of the phytophage flying was monitored using pheromone traps; the number of other garden pests was counted in accordance with the methods for registration tests of insecticides [9].

\section{Results and discussion}

The protecting system apple trees from diseases and pests is based on the use of chemical pesticides of the second or third hazard classes, while every year there is an increase in the frequency of treatments during one growing season to 20 or more. Therefore, the search for 
alternative methods for controlling the number of pests in the apple orchard is relevant and timely.

Today, the unset mating (MD) strategy is the most promising technology for the use of sex pheromones in the world, due to which the use of insecticides against lepidoptera pests has been significantly reduced [10-14].

The first use of pheromones began in 1959, but they weren't widely used, because there were no technologies capable of maintaining a constant concentration of a substance in the open air, low efficiency did not make it possible for this method to compete with insecticides [15]. Over the past two decades, the number of studies on the biosynthesis of insect pheromones and the mechanisms of their practical application in controlling the behavior of pests has increased.

A high abundance of $C$. pomonella was noted at the experimental site of ZAO Loris; up to 68 individuals were caught per trap in three days. As a result of the experiment, it was found that the damage to the fruits in the drop was $1.3-1.5 \%$, in the removable harvest, no damage to the fruits was noted, which corresponds to the results of the standard version, with the use of insecticidal treatments. In the control, the indicators of fruit damage were $83 \%$ in the drop and $61 \%$ in the harvest.

In addition to $C$. pomonella, a high abundance of Aphis pomi, Quadraspidiotus perniciosus, Tortricidae, Euzophera bigella ZELL was noted. In the control variant, the damage to E. bigella fruits was more than $50 \%$. As a result of the research, it was confirmed that the pheromones Shin-Etsu ${ }^{\circledR}$ MD CTT, D and BRIZ ${ }^{\circledR}$ have no side effects on other phytophages of the apple orchard, therefore, five spraying with insecticides was carried out on these pests.

In the experimental plot of the agricultural sector of Novomikhaylovskoye agricultural enterprise, the number of $C$. pomonella didn't exceed the economic injury level, and a moderate presence of E. bigella and Grapholitha molesta was also noted in the garden. During the season, two treatments were carried out against the pest complex, with ten sprays in the standard version. The effectiveness of the biorational method for controlling the number of $C$. pomonella using Shin-Etsu ${ }^{\circledR}$ MD CTT, D was $98.8-100 \%$, which is equivalent to the indicators obtained in the variant with the use of a chemical protection system (Fig. 1). When testing BRIZ ${ }^{\circledR}$ pheromones, results similar in efficiency were obtained.

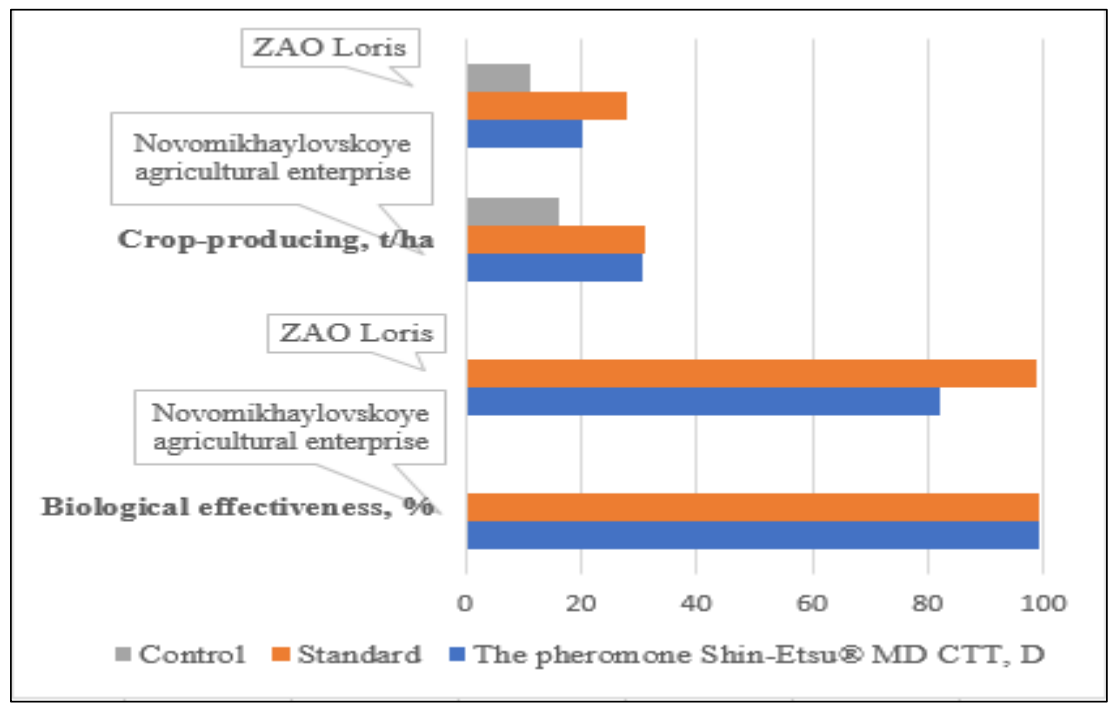

Fig. 1. Economic efficiency of the use of pheromone Shin-Etsu MD CTT, 2017-2019. 
The highest efficiency of the use of twin-tubes Shin-Etsu ${ }^{\circledR}$ MD CTT, D was noted in the Black Sea horticultural zone of the Krasnodar Territory - 98,8-100\%, which is equivalent to the standard. The cost reduction for the purchase of insecticides was $9089.2 \mathrm{rub} / \mathrm{ha}$, the profitability was $138 \%$, and the pesticide pressure was reduced by $70 \%$. The crop yield in the variants of the experiment was $30.5 \mathrm{t} / \mathrm{ha}$, the fruit standard nature was $98 \%$.

The use of attractants in the central zone is not cost-effective, since the pheromones on the market are products of targeted action only on one species of phytophage (C. pomonella), and the number of other fruit-damaging pests in the garden is higher than the economic injury level.

Experience of using Shin-Etsu® MD CTT in the 2016-2018 season in all regions of the Russian Federation showed high reliability and efficiency of the disorientation method. Studies have shown that the scheme can be applied both independently (for example, in organic gardens), and in combination with chemical treatments (integrated protection system) in the presence of a wide range of pests, with a constant influx of C. pomonella into gardens, with an extremely high the peak of summer.

\section{Conclusion}

The results obtained indicate that the Shin-Etsu ${ }^{\circledR}$ MD CTT, D and BRIZ ${ }^{\circledR}$ (RAK) disorientators are an equivalent alternative to insecticides used against Cydia pomonella. The use of pheromones in apple agrocenoses is recommended against the background of a low number of lepidoptera (Tortricidae, Tineidae) pests, this will reduce pesticide treatments to $70 \%$. When the number of $C$. pomonella is higher than the economic injury level in apple plantations, 2-3 treatments are necessary, but even with this, the pesticide load on apple cenoses decreases by $20-90 \%$. "The means list of production for use in the organic system farming on the basis of international principles of organic agriculture" allowed the use of pheromones for organic gardening.

\section{References}

1. M.E. Podgornaya, S.V. Prakh, Fruit growing and viticulture of South Russia, 48(6), 85-93 (2017) http://journalkubansad.ru/pdf/17/06/10.pdf

2. Z. Tian, Y. Zhang, Insect Mol. Biol., 25, 769-777 (2016) https://doi.org/10.1111/imb.12261

3. T. V. Dolzhenko, L. A. Burkova, O. V. Dolzhenko, Horticul. viticul., 4, 52-56 (2018) https://doi.org/10.31676/0235-2591-2018-4-52-56

4. F. Trona, G. Anfora, M. Bengtsson, P. Witzgall, R. Ignell, J. Exp. Biol., 213, 4291-4303 (2010) https://doi.org/10.1242/jeb.047365

5. P. Witzgall, P. Kirsch, A. Cork, J. Chem. Ecol., 36, 80-100 (2010) https://doi.org/10.1007/s10886-009-9737-y

6. V.A. Khilevsky, International scientific journal "Symbol of Science", 2, 19-21 (2016) https://cyberleninka.ru/article/n/upravlenie-chislennostyu-yablonnoyplodozhorki-spomoschyu-feromonov/viewer

7. R. Flückiger, Ander. Bio. J., 12-13

https://www.andermattbiocontrol.com/media/pdf/about-us/news/AndermattBiocontrolJournal 2019.pdf

8. S. Dutta, Chem. Advan. Mater. (2019) https://teletype.in/@dattad/yWxRlwHjL

9. J.Y. Yew, H. Chung, Prog. Lipid Res., 59, 88-105 https://doi.org/10.1016/j.plipres.2015.06.001 
10. S. Rizvi, J. George, G. Reddy, X. Zeng, A. Guerrero, Insects, 12, 484 (2021) https://doi.org/10.3390/insects12060484

11. D.R. Lance, D.S. Leonard, V.C. Mastro, M.L. Walters, J. Chem. Ecol., 42, 590-605 (2016) https://doi.org/10.1007/s10886-016-0732-9

12. C. Ioriatti, A. Lucchi, J. Chem. $\quad$ Ecol., 42(7), 571-583 (2016) https://doi.org/10.1007/s10886-016-0722-y

13. N. Eisner, E.M. Chasen, S.A. Steffan, Plant Science Symposium, 335731 (2016) https://www.ars.usda.gov/research/publications/publication/?seqNo115=335731

14. A. L. Il'ichev, M.D. Reinke, D.G. Williams, L.J. Gut, Gen. Appl. Ent., 41, 5-15 (2013) https://treefruit.msu.edu/research/Il'Chev etal 2012.pdf

15. A. Lucchi, E. Ladurner, A. Iodice, F. Savino, R. Ricciardi, F. Cosci, G. Conte, G. Benelli, Env. Sci Pollut Res 25, 9426-9442 (2018) https://doi.org/10.1007/s11356-018-1248-3 